\title{
Research on the Causes of the Destruction of the Qin Dynasty Jing Huang ${ }^{1, a}$ \\ ${ }^{1}$ China University of Political Science and Law, Beijing, China, 100088 \\ aemail,
}

Keywords: Legalist Thought, Cultural Integration, Autocracy, Law Enforcement

\begin{abstract}
Qin's law is invincible in the Qin period and it becomes a rapid decline of the Qin Dynasty. Many people think that the Qin Dynasty is due to the tyranny of the Qin Dynasty led to the demise of the Qin Dynasty, but summed up the historical experience, we found the problem or the emergence of the system above, especially at the legislative level. The law is in keeping with the reality of society at that time, and the promotion of productivity is a good law in order to maintain the normal functioning of the country.
\end{abstract}

\section{Introduction}

Qin Dynasty pursued the idea of law and law, the law did not change the basic, but this law in the Qin Dynasty when the invincible, and the same law to the Qin Dynasty, but led to the death of two. We will analyze the causes why the destruction of the Qin Dynasty come so fast. Qin country in the reunification of the world, the situation has undergone tremendous changes in the reunification of the Qin world before the Warring States period, at that time, the country is facing a merger war, although there are contradictions within the country, but the main contradiction is still derived from the outside. In the reunification of the world after the Qin, the world has been set and the Qin Dynasty has become the largest unified multi-ethnic country in Asia. In the era of traffic and information is not developed, the face of such an unprecedented empire, how to control is a problem, and predecessors have not had such a large country to manage the experience, so the country's main contradictions from the external contradictions Become an internal contradiction. At this time for the Qin country is facing a lot of problems, to be resolved. Then we will analyze the causes of the destruction of Qin, hoping to learn from the ancient experience for later use, it's important.

\section{The Legal Package of Measures of Qin Dynasty Cannot Keep Up with the Huge Expansion of Territory}

Such as the appointment and dispatch of officials, which was previously applicable to the Qin state in a small place in Qin, but in the Qin dynasty, the kingdom was greatly expanded, but it was still applicable to the former system Appointments have created a great deal of problems, and to the official, it is sometimes necessary for several months to transfer between the transfer and the dispatch, it take so much time which has caused some social problems.

In addition, after the reunification of the Qin Dynasty, in the economic and cultural differences exist in the region and the same law will inevitably produce some problems, such as some problems appear in the tax system. We know that Qin occupied the Guan zhong area, and merged with Xi Rong and Ba shu. Shu is the land of abundance, abundant rainfall, suitable for crop growth, in fact, Guan zhong region is the same. We now feel that the customs are dry and dry in Guan zhong, but through the literature, we can understand a lot of ancient climate information. "The Book of Songs • Qin Feng • the end of the South": "What is the end of the South? There are plum", "Historical Records" Carnival biography "said:" ... ... Wei Chuan acres of bamboo. "From these documents, that time Qin should be higher temperature rain plenty of water, suitable for crop growth. However, there is a problem with the uniform use of the tax system in the whole country, which is that the land in the Kanto area is relatively scattered and the per capita possession is not much. There is no environment suitable for the growth of crops as well as the same tax system. Resulting in a negative 
impact, but cannot lead to substantial fairness, which led to the people in the Guanzhong people are destitute. But we can also see that since the past has never had the experience of dealing with such a big country, the problems facing the Qin Dynasty are unprecedented, after the accumulation of experience and lessons learned to gradually improve the formation of a complete system applicable to the land of China.

\section{The Failure of Cultural Integration}

The so-called cultural integration refers to the process of mutual absorption, melting and reconciliation of different cultures. They absorb, integrate, accent, form and form changes, and gradually integrate into a new cultural system. Cultural integration is conducive to the promotion of people's unity and national unity, integration is not easy to produce many social problems, and even lead to the division of the country. Qin has six cultural integrations of the six countries, once Lv Buwei presided over the compilation of "Lu's Spring and Autumn", trying to orient the six countries of the essence of the ideological and cultural culture in a furnace, as the future of the unified empire theoretical basis, this time basically successful. After the reunification of the Six Kingdoms, the implementation of "burning book pit Confucianism", the implementation of "official as a teacher", "law to teach" cultural despotism, attempt to detain people's thinking, and refused to absorb the six countries thought and culture of the essence, led to the decline of Qin.

Not only China, but also in many parts of the world, there are cultural integration problems, different cultures and religious beliefs, often lead to the people of this region is divided into different groups, which is the starting point of many conflicts. For example, in today's Europe, there is a conflict between Islam and Christianity because of differences in religion and culture. Although the world economy and politics are as one, but civilization is not as political and economic as, but more and more to show the opposite trend.

China's Confucian culture and Islamic culture, has its deep heritage, in the previous colonial movement was suppressed, and now to be revived, the Islamic culture, the existence of internal Sunni and Shiite, to be integrated. In today's world, the white culture is mighty, and also in the field of economics. But for China's Confucian culture and Islamic culture, they still think they are much better than the white culture, they even think they are the best of all in this world. The highly economic growth in East Asia (China, Korea, Japan), they more and more likely to believe that it's the advantage of its culture makes them make it. China's Confucian culture praises highly the collectivism while the white culture praises the individualism, but now we can see the collectivism seems can more boost the economic development. The economic in the Islam world is not good, but for some raisons, they still have the cultural superiority, they think they are the best. We can see, in many Islamic states, their cultures and customs are well preserved, just like Qatar, Saudi Arabia, Algeria, etc. But the problem for the Islamic states is that they are in the middle of the Eurasia, it's a rapier for the Islamic states. We all know that in the peace time, because they are in the middle of the Eurasia, the trade will flow pass the Islamic states, so in the peace time the Islamic states will develop fast and no matter the west or the east don't want it happen, so the Islamic states are always in confusion and there are always wars happen here.

The importance of cultural integration is that each culture has its own unique advantage, in line with the characteristics of their free groups. More heavy medicine is that for different cultural groups, they are more likely to accept each other. Such as the Confucian culture centered on China, and the ancient Greek and Roman culture of the White Humanity Center, Muslim-centered Muslims. People of the same kind of culture are more likely to bring close feelings. China, Korea, and Japan, the three countries, although they have some divergences, and even the territorial disputes, when they face the West, they can still make common cause with some stand, of course it's the close feelings makes them to do that. Now we can see that among China, Korea and Japan, there are still many displeasures due to historical reasons. If the three countries can put away their prejudices, and they can integrate to be an economic entity, it will be the largest economic entity in the world and benefit the three countries. The Southeast Asia is also influenced much by the China's Confucian culture, people in the Southeast Asia and in China are more likely can know each other. 


\section{The Tyranny of the System}

We know that the Qin pursued the idea of legalists and pursued the administrative system of authoritarian centralization. Things are two sides of the sex, despotism and democracy is only the choice of people only, they have their own advantages and disadvantages. The authoritarian system determines the great bad, for the rulers, due to centralization, many measures can be implemented immediately and the individual will be able to act on the country. So if a country's monarch is wise, then the autocratic regime is good, a large number of good policies can be developed and implemented, the country can quickly develop and grow; but if the monarch is not wise, then the authoritarian system is a kind of disaster And will also lead to rapid decline and corruption. For the democratic system, because the decision-making within the department there are more compromise and game, then it will not be good and bad, will maintain a relatively stable state. Here we take the fourth republic of France as an example, we know that France is Europe's China, France as a traditional European power in Europe is relatively more authoritarian. After the end of World War II, the people were completely disgusted with the autocracy, so when the Constitution of the Fourth Republic of France was enacted, people tried to demand democracy, so the National Assembly had almost all the rights, the Senate did not check the National Assembly. Coupled with the French Republic of France in the fourth national conditions, the French multi-party system, party competition resulted in many policies that are conducive to economic development because the parties are infighting, so after the war the French economy is not much improvement. Later, the return of General de Gaulle, the French regime for the semi-presidential system restores the decline. To exaggerate the power of democracy, there will be such a drawback. There we can truly see the defect of the democratic system, even in today's France, it still exists. Now, in France, the people here are very mighty, on the other hand, the government in France seems weak. The benefit system in France is developed, for some people, they do not work, but they can get amount of money to maintain the life. When someone is not satisfied with his job, he can choose not work, because for the with stand work, they work, or they do not work, they can get almost as much. So many people are on the dole and they don't want to work, it leads a society problem.

So the autocratic system, it is easy to lead great bad, but the Qin Dynasty to implement authoritarian system, history and just let Qin two people such as when the monarch, leading to the rapid demise of the Qin Dynasty. History is also a coincidence, if it is Fu on the Prince, then it may be another situation. The autocratic system of Qin Dynasty makes the China to be unify, it's his contribution, and it establish a stable political system for China, we can see that, the feudal dynasties in China exist more than 2000 years, but the political system that the Qin Dynasty create change very little. Even in today's world and culture, it still can play a role. The western countries have been influenced much by the ancient Greek civilization and the ancient Rome civilization, especially in the institutional level, the ancient civilizations has an influence on today's world, sometimes make us feel that the economic, the technology, the way of life have changed so much, but, something essential never change.

\section{Too Harsh Enforcement of the Law}

Legalist thought emphasizes the development of the law, it is necessary to strictly enforce, no one can be exception. Strict compliance and enforcement of the law in today's society seems to be commendable, but in the Qin Dynasty under the historical conditions, there are indeed problems. We know that the law is limited, one of which is reflected in the law cannot be timely mistakes. The law is stable, continuous, but social life is constantly evolving. The limitations of the law are also reflected in the stability of the law and its limitations, the law should avoid the change, emphasizing the stability of the law. But stability also means a certain degree of conservatism, in the period of social transformation, the law cannot follow suit yesterday is the time of this change. In the period of social transformation, the stability of the law will become a hysteresis inevitably stumbling the pace of social progress.

The limitations of law can exist even in a stable society, such as France has issued a number of 
decrees and the purpose is to protect the interests of tenants to achieve the purpose of protecting vulnerable groups. At that time, people thought that the promulgation of these decrees, the interests of tenants can be a very good protection, but in fact not promulgated these decrees, many landlords that some of the rights and interests before now, some landlords think the rent is a piece Troublesome things, so do not rent a house, but led to the rise in rent prices, in essence, but did not protect the interests of tenants. This is a modern example, but we think, at that time of the Qin, the reunification of the six countries, and to manage such a large country, the problems and changes facing the unprecedented. If too harsh to implement the law, then it will inevitably bring bad consequences, thus speeding up the decline of the dynasty. Of course, we do not advocate the implementation of the law is not strict, but in that unprecedented change, if you can give a period of flexible period, within the prescribed period of time to apply the law can be flexible, the way the legal application of the situation, the final results Timely adjustment of the law will get better results.

\section{The Vested Interests Level Has Become Less}

We know that the idea of legalists emphasizes reward and punishment. In the Qin Dynasty is not unified when the world, or when the Qin, that time, facing the war. Qin carried out the twenty military rank system was the emerging landlord class to improve the combat effectiveness of the army to take a measure. Shang Yang regulations: Qin soldiers as long as the gains of the enemy "armor" (enemy officers) a head, you can get a title "public", Tian Yi dump, a house and a servant. In addition, the Qin also take the eloquent measures, not only to give the title, but also to win the title, we can see "the prison, the jazz since two or more, there is a crime is demoted, Criminal has been ", the establishment of a flexible flow mechanism. So that the invisible to create a class up the flow of channels, and vested interests are at least a certain area of the strong, they will be more maintenance of this system, the country will be more stable. However, after the reunification of the Qin, the world has been set, this upward circulation channel was blocked, but at that time did not produce the imperial examination system, so in the loss of this legal class up the way of circulation, leaving people only Harsh criminal law, resulting in the short-lived Qin Dynasty.

When it comes to the Han Dynasty, it creates the imperial examination system, so for people there, there is a legal class up the way of circulation, but it does not work very well. Because at that time, there exists the paper, but it's really very expensive. There exists the same thing at the Middle Ages. So at that time, overwhelming majority who can pass the exam come from the rich family. The class floats very little, the king and the aristocratic family are in power. It's in the Song dynasty, where the papermaking technology is widely used, and the paper, the books become much cheaper than before that the normal family can afford, that much poor people can pass the imperial examination system and be a government official. The class did float, many primes ministers came from a poor family, but the society of China became more and more rigid. Because the imperial examination system makes an on the spot investigation only on Neo-Confucianism, it does not review the natural science, so the nation becomes rigid.

\section{The Implementation of Tyranny}

Qin dynasty pursued the idea of legalists, the implementation of misdemeanor which is the direct cause of Qin's death. At the period of Qin shihuang, they forced farmers to servitude, massive construction projects, the construction of large-scale palace, tomb, to the working people has brought great difficulties. In order to consolidate the rule, Qin Shihuang is only with the harsh means to suppress the rebels, and the implementation of severe penal system. Qin rulers to promote "misdemeanortion", sentencing harsh, the death penalty, there are waist cut, abandoned the world, with five sentences and other torture, as well as the palace and other brutal torture, and Qin Qin's special heavy The These are the rapid death of the Qin Dynasty buried a hidden danger, but not the main reason. Qin Shi Huang is brutal, but not the most brutal; Qin Dynasty penalty is cruel, but not the most brutal of all. Qin Shihuang burned the book Confucianism to kill more than four hundred 
and seventy people, than the Qing dynasty once even the literary prison is far less than; Qin Dynasty criminal law, although very strict, but there is no future kind of thousands of stance death and death of the family Criminal law brutal. The implementation of tyranny is one of the reasons for the rapid demise of the Qin Dynasty, but it is not the main reason.

\section{Not paid enough attention on the moral}

We know that the Qin dynasty affect the doctrine of severe punishment, and the Legalism is the dominate thought at that time. We think they do not pay enough attention on the moral, which lead to the failure of the Qin Dynasty. The jungle society is what the society should to be, just like the animal world, and there is no doubt that the mankind is a sort of animal. But the mankind has the sympathy, which makes the world become more and more equal. Without moral, the society will go bad. We all know that the water seeks its own level, and also the mankind society. But sometimes, the water goes up. Why does it goes up, the power source makes the water make it. In the society, we should also search the power source. In this paper, we think it's the sacrifice oneself of people that will become the power source which will make the society thriving. Someone does sacrifice, which makes the society change, it ceases to be a jungle society, the people sacrifice, just like there is a power source which makes the water goes up. We think it's the moral that will make the people want to sacrifice.

Now we imagine, in this world, there exist a perpetual motion machine, we give the machine a push, and it will work everlasting. But in this world, the perpetual motion machine never can exist, we should give a power source to the machine to maintain its work. The society also need the power source to maintain, if not, it will decline or even perish. No matter the West or the East, we think they realize the same thing. In the West, they draw the essence from the Christian religion to raise the level of morality. For the East, they choose the Confucianism to raise the level of morality that makes the society be more stable than before. The core concept of Confucianism is benevolence, which is created by Kong $\mathrm{Zi}$. We should value justice above material gains, and the filial piety is plus important in the system of Confucianism. In the Northern and Southern Dynasties, the Buddhism was introduced in China. The Buddhism is a philosophy, which has an influence on the dominance hierarchy in China. The Buddhism has affected also the Confucianism much, and after, the essence of the Confucianism changes a lot. The problem in China is that it's a society of unitary in the field of philosophy and political system. On the other hand, the West is always polyphyletic in the field of political systems. The polyphyletic in the field of political system make the West check and balance, and makes the West full of energy because there are always concurrences. The West has his competitors, so he wants to develop and he will absorb the quintessence of other countries. China is unitary and there is little match, so he lost his energy. In the late Qing Dynasty, the moral degenerate. No matter the Qing Dynasty, it's GDP is more than the other countries, but it still loses so many wars, just like the First Opium War (Britain's invasion of China, 1840-1842), the Second Opium war (1856), the Sino-Japanese War (1894), etc. The economic is very important, but the construction of the moral is more important.

\section{Conclusion}

Qin Dynasty, the reasons for the rapid demise of multiple and complex, summed up the reasons for the demise of the Qin Dynasty, still can give many profound inspirations. First of all, for the ruler, we should pay attention to the work of legislation, the law should be considered in all aspects of the operation of the real world, we should not be too subjective, and the development of the law should also promote the social progress and promote the development of economics. The Second conclusion, how to establish a sound mechanism for selecting elites, breaking the stratification, and making them serve the country and society is also very important. Third, in the face of social transformation, in the maintenance of legal stability and authority under the premise, should also be flexible application of the law in order to allow the country to go smoothly and smooth. The forth conclusion, although the development of the economics is very important, the construction of moral 
is more important and it's the real key that will determinate whether a country can develop sustainably. The concept "to govern the country with law and moral" of the Confucianism has still something to learn from today's world and from us. In fact, for most of the countries, the law changes not much, because law should be stable, on the other hand, there does not exist a perfect law, every law has its disadvantages. At the beginning, the disadvantages are very little, but the time lapse, these disadvantages will blow up, only the moral can solve this problem. Qin Dynasty has been destroyed for long time, but we can still learn lesson from it.

\section{References}

[1] Yang Jiayou "Qin on Xi Rong, Bashu merger" history teaching, 1986. 07

[2] Meng Xiangcai "on the Qin culture of the six countries of the six cultural integration", Yantai University, Vol. 18, No. 4

[3] Huntington "The Clash of Civilizations", Xinhua Press, January 2013 edition.

[4] Wang Yaohai "Shang Yang reform", 2014, Social Science Literature Publishing House

[5] Zhang Jinfan, "History of Chinese Legal System", 2003, Higher Education Press

[6] Zhang Linfa "King on the study of violence and death Qin" Tang Dynasty Journal No. 15 No. 2 